Steven Yale, MD, FACP Department of Internal Medicine, Marshfield Clinic Director of Clinical Research, Marshfield Clinic Research Foundation Marshfield, Wisconsin

\section{Sensitivity and Specificity}

Editor - In the Authors' Reply to the letter "Sensitivity and Specificity of Tests of Liver Injury" in the November 2004 issue of Clinical Medicine \& Research, the statement "It is true that no single test of liver injury is either highly sensitive or specific" would be more accurate if it read "It is true that no single test of liver injury is both highly sensitive and specific". It is easy to come up with a test (for anything) that is either perfectly sensitive or perfectly specific; the test is of little use without some degree of both.

1. Musana KA, Yale SH, Abdulkarim AS. Authors' reply: Sensitivity and specificity of tests of liver injury. Clinical Medicine \& Research 2004;2:205.

Richard Berg, MS Biostatistics and Bioinformatics Core, Marshfield Clinic Research Foundation Marshfield, Wisconsin
The name and credentials of Dr. James Freeman were incorrectly listed in the 2004 Reviewer Index that appeared in the November 2004 issue of Clinical Medicine \& Research (2004;2:279-281). The correct listing should read "James R. Freeman, DO. Marshfield Clinic - Eau Claire Center. Eau Claire, WI, USA". We sincerely apologize for these errors.

Editorial Staff Clinical Medicine \& Research 